Acta vet. scand. 1971, 12, 607-610.

Brief Communication

\title{
DETERMINATION OF AMPHETAMINE IN URINE AND BLOOD
}

The determination of amphetamine in body fluids is of interest in veterinary toxicology because of the possible use of amphetamine in the doping of race horses. Many types of methods for its detection and determination have been developed. In the newest methods gas chromatography and mass spectrometry have been applied, making it possible to detect and identify $1 \mu \mathrm{g}$ amphetamine in blood samples (Bonnichsen et al. 1970).

The rôle of amphetamine in the doping of race horses has recently been reviewed by Schubert (1967) in a supplement to this journal. In his own experiments with horses Schubert used thin layer chromatography and could detect amphetamine in samples of $200 \mathrm{ml}$ urine after $150 \mathrm{mg}$ amphetamine sulfate i.m. The concentration of amphetamine in the urine was estimated to be in the order of $0.1 \mathrm{mg}$ per $100 \mathrm{ml}$ urine ( $1 \mu \mathrm{g}$ per $\mathrm{ml}$ ).

In 1958 the authors developed a quantitative method for the determination of amphetamine in urine and blood based upon the principle of coupling amphetamine with p-nitrobenzenediazonium chloride (Beyer \& Skinner 1940) at the School of Veterinary Medicine, Davis, California. The method was sensitive and offered reproducible results when conditions such as time, temperature, and especially $\mathrm{pH}$ were maintained at optimal values (Fig. 1). The method and the results were not published at that time since the newer chromatographic methods were supposed to be superior to the colorimetric methods. By using steam distillation of $25 \mathrm{ml}$ alkalinized urine, extraction of distillate with hexane and diazotizing at $\mathrm{pH} 7.25$ and $38^{\circ} \mathrm{C}$ it was possible to detect amphetamine down to $2.5 \mu \mathrm{g}$, corresponding to a maximal sensitivity of $0.1 \mu \mathrm{g}$ per ml urine. The calibration curve was a straight line over a sufficient range of concentrations. The recovery of amphetamine sulfate in this method was about $65 \%$. In a similar way amphetamine could be determined in blood after precipitation with trichloroacetic acid and centrifugation. 


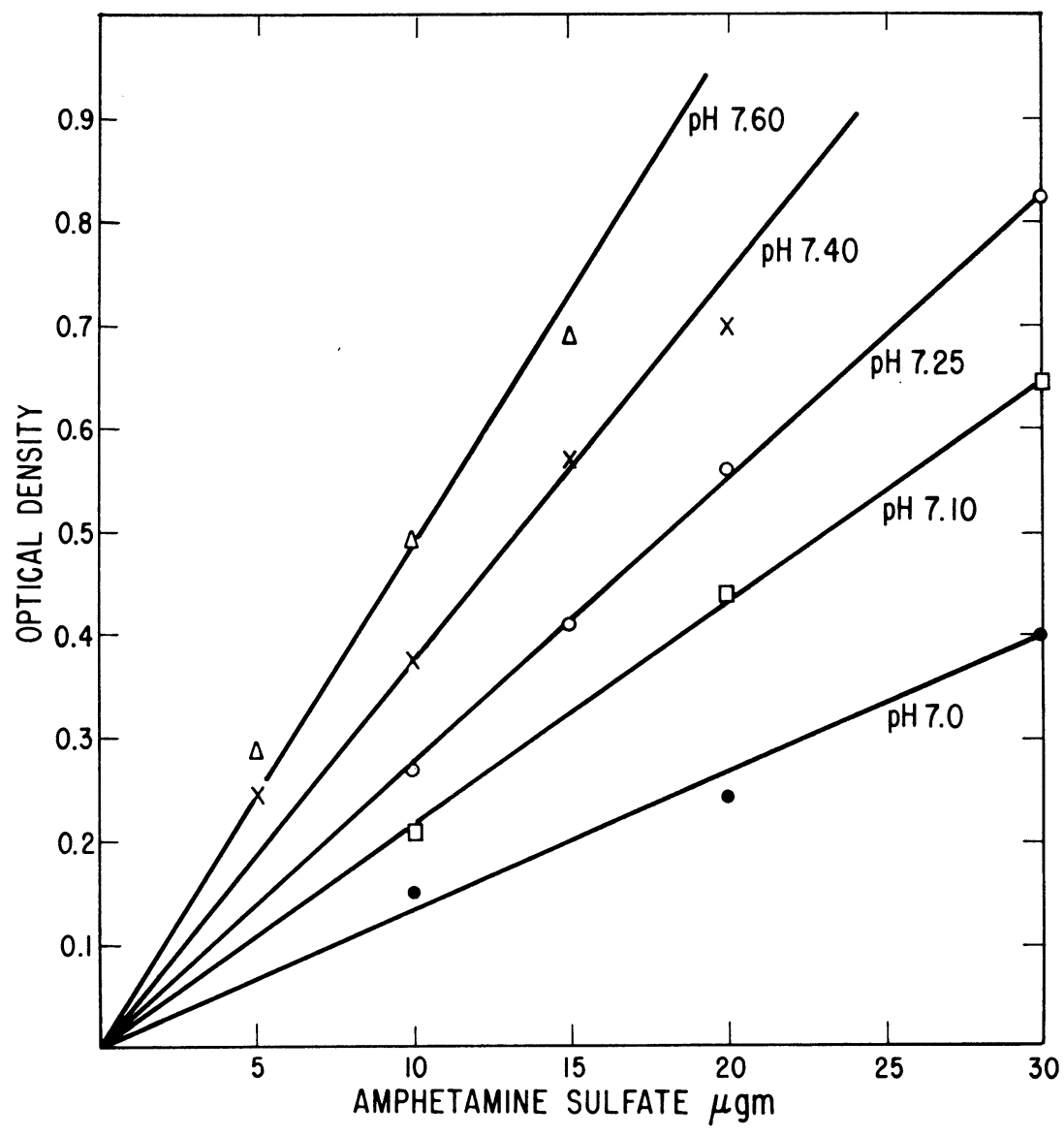

F ig u r e 1. Calibration curves for amphetamine sulfate at different values of $\mathrm{pH}$. (Diazo reaction $\max .530 \mathrm{~m} \mu$, min. $430 \mathrm{~m} \mu$ ).

Our experiments with amphetamine in man, dog, and horse may be of interest since they give information about the detectable concentrations of amphetamine and the rate of excretion.

The experiments in human subjects (Table 1) indicate that after moderate doses of amphetamine detectable concentrations may persist in the urine for $48 \mathrm{hrs}$., confirming the results of previous investigations.

The experiments in dogs (Table 2) show that very large doses must be applied to give a detectable concentration in the blood.

Usual doses of amphetamine (Table 3) given intramuscularly to horses did not reach a detectable concentration in the blood 
Table 1. Determination of amphetamine in human urine $(\mu \mathrm{g} / \mathrm{ml})$.

\begin{tabular}{cccccccccccc}
\hline & \multicolumn{11}{c}{ Hours } \\
$\begin{array}{rlccc}\text { Dose orally } \\
\mathrm{mg} / 75 \mathrm{~kg}\end{array}$ & 3 & 4 & $51 / 2$ & 7 & 12 & 20 & 24 & 28 & 33 & 48 & 50 \\
\hline 5 & 0.4 & & 1.3 & & 0.8 & 0.3 & & & & & \\
5 & & 2.0 & & 3.5 & & & & 0.8 & & & neg. \\
10 & & & & 1.6 & 0.6 & & 1.6 & 2.7 & 1.3 & 0.4 & neg. \\
\hline
\end{tabular}

Table 2. Determination of amphetamine in dog plasma $(\mu \mathrm{g} / \mathrm{ml})$.

\begin{tabular}{|c|c|c|c|c|c|c|c|c|}
\hline \multirow{2}{*}{$\begin{array}{c}\text { Dose s.c. } \\
\mathrm{mg} / \mathrm{kg}\end{array}$} & \multicolumn{8}{|c|}{ Hours } \\
\hline & $1 / 2$ & $3 / 4$ & 1 & $11 / 2$ & 2 & 3 & 4 & 5 \\
\hline 1.0 & & & & & neg. & & neg. & neg. \\
\hline 1.0 & 0.2 & & 0.1 & & 0.1 & & & \\
\hline 3.0 & & 0.5 & & 0.3 & & 0.2 & & 0.16 \\
\hline
\end{tabular}

T a b l e 3. Determination of amphetamine in horse urine $(\mu \mathrm{g} / \mathrm{ml})$.

\begin{tabular}{cccccc}
\hline \multirow{2}{*}{$\begin{array}{l}\text { Dose i.m. } \\
\text { mg/500 kg }\end{array}$} & 2 & 6 & 9 & 12 & 24 \\
\cline { 2 - 6 } & 0.2 & 0.4 & & & neg. \\
200 & 0.1 & 1.0 & & & neg. \\
200 & 4.6 & 5.2 & 1.4 & 1.0 & neg. \\
\hline
\end{tabular}

samples. Amphetamine is more rapidly eliminated in horse, than in man, and could not be detected in the urine longer than $12 \mathrm{hrs}$. after the administration.

\section{O. Dybing}

The Department of Pharmacology and Toxicology, Veterinary College of Norway, Oslo.

\section{S. A. Peoples}

The Department of Pharmacology,

School of Veterinary Medicine,

University of California, Davis, USA.

\section{REFERENCES}

Beyer, K. H.\& J. T. Skinner: The detoxication and excretion of beta phenylisopropylamine (Benzedrine). J. Pharmacol. exp. Ther. $1940,68,419-432$. 
Bonnichsen, R., A. C. Machly, Y. Mårde, R. Ryhage \& B. Schubert: Determination and identification of sympathomimetic amines in blood samples from drivers by a combination of gas chromatography and mass spectrometry. Z. Rechtsmedizin 1970, 67, 1926.

Schubert, B.: Identification and metabolism of some doping substances in horses. Acta vet. scand. 1967. Suppl. 21.

(Received September 25, 1971). 